\title{
0 ensino de Educação Popular em Saúde para o SUS: experiência de articulação entre graduandos de enfermagem e Agentes Comunitários de Saúde
}

Maria Carmélia Sales do Amaral(a)

Andrezza Graziella Veríssimo Pontes ${ }^{(b)}$ Jennifer do Vale e Silva ${ }^{(c)}$

\section{Introdução}

A Constituição Brasileira de 1988 incorporou ao seu texto o conceito ampliado de saúde construído pelo Movimento de Reforma Sanitária Brasileira, que tinha como fundamento a teoria da determinação social do processo saúde/doença. Isso exigiria mudanças na organização da produção dos serviços de saúde e na formação dos trabalhadores do SUS, com vistas à universalidade, equidade e integralidade da atenção.

Nesse contexto, a Educação em Saúde torna-se uma ação fundamental para garantir novas práticas sanitárias. Para tanto, é preciso superar a Educação em Saúde historicamente hegemônica, que tem sido instrumento de dominação do saber da elite e de responsabilização dos indivíduos pela redução dos riscos à saúde ${ }^{1}$. Buscando romper com a tradição autoritária e normalizadora da relação entre os serviços de saúde e a população, destaca-se o movimento da Educação Popular em Saúde $(E P S)^{2}$ Um dos maiores desafios desse movimento é sua incorporação nos cursos de graduação na área de saúde, na formação de Agentes Comunitários de Saúde (ACS), na educação permanente dos trabalhadores do SUS e nos cursos de pós-graduação ${ }^{3}$.

Para contribuir com o debate da formação em EPS, o presente artigo objetiva sistematizar e avaliar a experiência da disciplina Educação Popular em Saúde de um curso de graduação em Enfermagem, que testou inserir Agentes Comunitários de Saúde como discentes, tendo como premissas o entendimento de que o espaço da formação em Saúde é um lugar propício ao desenvolvimento de estratégias de qualificação dos trabalhadores do SUS e, ao mesmo tempo, a percepção desses atores como facilitadores do processo de ensino-aprendizagem. O mérito da experiência está em fazer dos serviços de saúde espaços de reflexão dos aprendizes de cursos de graduação e fazer da sala de aula universitária espaço de qualificação dos ACS.

\section{A formação em saúde/enfermagem para o SUS}

A história da formação em Saúde no Brasil é marcada pela desarticulação entre o ensino e as necessidades sociais de saúde. A problemática em torno da capacidade do sistema de saúde nacional em responder às necessidades de saúde entrelaça-se ao desafio do sistema educacional em formar profissionais capazes de intervir nessa direção.

\footnotetext{
(a,b) Departamento de Enfermagem, Faculdade de Enfermagem Universidade do Estado do Rio Grande do Norte.

Rua Dionísio Filgueira 383, Centro. Mossoró, RN, Brasil. 59610-090. carmeliasales@bol.com.br andrezzagazi@hotmail.com

(c) Departamento de

Ciências Biomédicas,

Faculdade de Ciências da Saúde, Universidade do Estado do Rio Grande do Norte. Mossoró, RN Brasil. jennifer_vale@hotmail.com
} 
Historicamente, o modelo que tem orientado o processo de formação dos trabalhadores da área de saúde é de abordagem biologicista, medicalizante e procedimento-centrada. O modelo pedagógico hegemônico de ensino é centrado em conteúdos, organizado de maneira compartimentada, isolada, fragmentando os indivíduos em especialidades clínicas, centrando as oportunidades de aprendizagem na clínica, incentivando a especialização $\operatorname{precoce}^{4}$ (p. 82).

Com o movimento de Reforma Sanitária Brasileira, fortaleceu-se a crítica a esse modelo de formação, a qual se materializou em Diretrizes Curriculares Nacionais (DCN) para a graduação em Saúde. A aprovação dessas DCNs ocorreu, em sua maioria, entre os anos de 2001 e 2002, e pressupôs que a formação em Saúde deve contemplar o sistema de saúde no país e a integralidade da atenção à saúde.

No caso específico da Enfermagem, as DCNs foram fruto de grande e intensa mobilização da categoria a partir de 1986, impulsionada pela Associação Brasileira de Enfermagem (Aben), com vistas à construção de novas bases teóricas e metodológicas que se aproximassem das necessidades de saúde da população ${ }^{4}$.Assim, as diretrizes afirmam que a formação do enfermeiro "deve atender às necessidades sociais da saúde, com ênfase no Sistema Único de Saúde (SUS) e assegurar a integralidade da atenção e a qualidade e humanização do atendimento" ${ }^{5}$ (p. 2).

Nesse sentido, a construção do SUS tem requerido novas formas de fazer saúde e, consequentemente, tem demandado das instituições formadoras um perfil de trabalhadores de saúde coerente com seus princípios e diretrizes.

As atuais DCNs dos cursos de graduação em Saúde assumem essas demandas ao definirem competências e habilidades que, em muito, extrapolam a formação tecnicista dos profissionais de saúde, até então, presente no Brasil. Segundo Miranda ${ }^{4}$, essas DCNs partem da compreensão de que a formação nessa área deve contemplar o sistema de saúde no país e a atenção integral à saúde.

Mesmo diante da indicação dessas Diretrizes, há, nesse campo científico, disputa de interesses, que podem ser complementares ou antagônicos ${ }^{6}$, premidos pela força do capital, que tenta impor a lógica de sua reprodução ${ }^{7}$. Assumir as demandas que o SUS coloca para a universidade é também um compromisso ético e político dos seus atores.

Um dos desafios do SUS à formação em Saúde é a articulação do ensino com o serviço e a comunidade. Na formação, as práticas educativas de aproximação do ensino-serviço com a comunidade devem ser (re)pensadas na perspectiva de fortalecer a participação social no sistema supracitado, destacando-se, para isso, a Educação Popular em Saúde como forma de estreitar a distância entre os serviços de saúde e a população.

\section{A Educação Popular em Saúde e o SUS}

A EPS pode ser compreendida como um modo particular de reconhecer e enfrentar os problemas de saúde mediante o diálogo com as classes populares, o respeito às suas culturas, o reconhecimento dos seus saberes como válidos e tendo como substrato o corpo teórico da Educação Popular, formulada por Paulo Freire no Brasil ${ }^{3}$.

Constituída no contexto de lutas populares e formulações teóricas em favor de melhores condições de saúde para a população que permearam o Movimento Sanitário Brasileiro a partir da década de 1970, a EPS emergiu do encontro de atores - trabalhadores de saúde, estudantes e professores universitários, segmentos da igreja e movimentos sociais -, na confluência entre distintas correntes teóricas - cristianismo, humanismo, socialismo - que resultaram na elaboração de um movimento de ruptura das práticas hegemônicas de Educação em Saúde de caráter preventivista, alicerçadas na Biomedicina e materializadas em prescrições de comportamento feitas de forma unilateral pelos profissionais de saúde ${ }^{8}$.

A EPS busca, além da construção de uma consciência sanitária capaz de reverter o quadro de saúde da população, a intensificação da participação popular, contribuindo para a promoção da saúde ${ }^{9}$. Ela parte do pressuposto de que o educando possui um saber prévio, construído em sua história de vida, sua prática social e cultural, que the serve de ponto de partida para a aquisição de novos 
conhecimentos. A educação se constitui como um processo de busca e de invenção ou reinvenção que parte da ação e da reflexão do homem sobre o mundo, para transformá-lo. A problematização das experiências ou situações vividas constitui um desafio para a transformação e, portanto, uma fonte para a organização do conteúdo do processo educativo ${ }^{10}$.

A Educação Popular atravessou as décadas de 1980 e 1990 como movimento e acumulou atores e instituições no âmbito da sociedade ${ }^{11}$. A partir dos anos 2000, foi efetivamente inserida no aparelho estatal, assumindo a condição de objeto de gestão no escopo da Política Nacional de Saúde e delineando caminhos que viriam culminar na elaboração de uma Política Nacional de Educação Popular em Saúde, aprovada em 2012, no Conselho Nacional de Saúde.

A implementação dessa política nos diversos âmbitos do sistema de saúde significou a constituição de ações envolvendo práticas de saúde, processos de formação dos profissionais, incremento da participação popular em saúde e do controle social, além da produção de conhecimentos a ela relacionados ${ }^{12}$, o que nos dá a dimensão de sua abrangência e, sobretudo, de sua importância para a consolidação do SUS.

\section{O Agente Comunitário de Saúde e a Educação Popular em Saúde}

As primeiras experiências com agentes de saúde, no Brasil, foram de iniciativa de organizações religiosas, em especial, católicas, na formação e utilização de ACS como força de trabalho em saúde, com a finalidade de redefinir as relações estabelecidas entre profissionais e população. Em seguida, ocorreram outras experiências vinculadas a organizações não governamentais e instituições acadêmicas nas quais os profissionais atuavam em saúde pública e comunitária ${ }^{10}$.

Essas experiências conformaram as bases para a implantação do Programa de Agentes Comunitários de Saúde (Pacs), em 1987, no estado do Ceará, com o objetivo de oportunizar emprego para as mulheres em um cenário marcado pela seca e, ao mesmo tempo, contribuir para a queda da mortalidade infantil, com a realização de ações de saúde voltadas para a mulher e para a criança ${ }^{13,14}$.

A vivência cearense nesse contexto foi institucionalizada pelo Ministério da Saúde, em 1991, e, dessa forma, implantada em nível nacional. Em 1994, o Pacs foi incorporado pelo Programa Saúde da Família (PSF) como estratégia de reorganização da atenção básica no país.

Como integrantes do PSF, os ACSs tiveram suas ações ampliadas. Saíram do foco materno-infantil para abranger também a família e a comunidade. Além disso, incorporaram novos saberes e práticas, em especial, no campo político e social, uma vez que os agentes constituem, historicamente, elo entre o serviço de saúde e a comunidade.

Bornstein ${ }^{10}$ acrescenta que o papel de mediação, exercido pelo ACS, pode comportar algumas contradições: o agente pode atuar como facilitador ou como empecilho na mediação e no diálogo entre os saberes e práticas da comunidade e dos serviços de saúde; o risco de exercer uma prática educativa dominadora; o fato de a educação buscar o convencimento da população com relação ao que deve ser feito; a assimilação por parte do agente das regras instituídas e sua reprodução de forma mecânica.

Assim, a Educação Popular pode representar uma ferramenta significativa para o trabalho do ACS, uma vez que possibilita a superação do entendimento, historicamente arraigado no interior do serviço de saúde, de que o saber da população é insuficiente e, dessa forma, inferior; quando, na realidade, devemos vê-lo como um saber apenas diferente.

\section{A experiência}

A disciplina Educação Popular em Saúde é um dos componentes curriculares do curso de graduação em Enfermagem da Universidade do Estado do Rio Grande do Norte (UERN). A iniciativa de inserir os ACSs nessa parte da formação acadêmica teve origem nas experiências acumuladas em disciplinas da área da Saúde Coletiva, ministradas nesse curso de graduação, que permitiram identificar a demanda de qualificação dos agentes de uma equipe de Saúde da Família em temas que contribuíssem para o fortalecimento do SUS. 
Observou-se que os ACSs precisavam (re)qualificar as ações educativas de modo a superar a concepção positivista de Educação em Saúde de práticas consideradas "impositivas, prescritivas de comportamentos 'ideais', desvinculadas da realidade e distantes dos sujeitos, tornados objetos passivos de intervenções, na maioria das vezes, preconceituosas, coercitivas e punitivas"15 (p. 13).

Essa superação deveria caminhar para a realização de ações de EPS junto com as comunidades, a partir de sua realidade de vida e trabalho, problematizando-a na perspectiva de desenvolver a crítica social de situações e ideologias naturalizadas ${ }^{15}$ e, nesse sentido, contribuir para o fortalecimento da participação social no SUS.

A disciplina Educação Popular em Saúde foi pensada de modo a assumir essa demanda de capacitação dos ACSs nesse tema, levando em consideração a premissa de que "o ensino em saúde guarda o mandato público de formar segundo as necessidades sociais por saúde da população e do sistema de saúde"16 (p. 47) e utilizando como estratégia importante a articulação ensino-serviço.

O planejamento da disciplina foi pactuado com a Secretaria Municipal de Saúde e com uma equipe de Saúde da Família, a fim de se viabilizar a participação dos ACSs. A disciplina seria um espaço simultâneo de formação de graduandos de Enfermagem e de capacitação para os agentes, que participaram dos 15 encontros semanais da disciplina, com duração de 4 horas/aula cada um, totalizando 60 horas/aula. Ao final, cada agente recebeu um certificado de "Curso de Capacitação em Educação Popular em Saúde para Agentes Comunitários de Saúde", emitido pela UERN.

A disciplina foi ministrada a uma turma de 25 graduandos do segundo período de Enfermagem e cinco ACS e possibilitou a construção das seguintes competências: (1) Conhecer o contexto em que se inserem as práticas educativas em saúde e o projeto de saúde por elas defendido - atores, objetivos/finalidades e meios/instrumentos de trabalho utilizados nas concepções do processo educativo; (2) Atuar em consonância com a concepção de saúde resgatada pelo SUS por meio de seus princípios, na perspectiva de implementar ações de Educação em Saúde que visem à promoção da saúde e à autonomia dos sujeitos; (3) Conduzir e propiciar a discussão e a revisão de práticas de Educação em Saúde hegemônicas de cunho normativo, impositivo e verticalizador; (4) Conhecer historicidade, conceitos, objetivos e práticas da Educação Popular em Saúde e sua importância para o SUS; (5) Desenvolver ações de EPS.

Os conteúdos foram divididos em três unidades: (1) Processo saúde-doença e as práticas Educativas em Saúde; (2) Educação Popular em Saúde: conceitos e práticas; e (3) Construção de projetos de intervenção de EPS. Adotou-se a pedagogia da problematização, partindo-se da realidade concreta das microáreas de abrangência dos ACSs.

Inicialmente, os graduandos e os ACSs foram divididos em cinco grupos, nos quais cada agente ficava com cinco alunos para realizarem, munidos de um roteiro norteador, uma captação da realidade no território da equipe de Saúde da Família, para, assim, conhecerem como vivem e trabalham as pessoas dessa área. A vivência foi apresentada e, em seguida, discutida em diálogo com os teóricos. Para tanto, foram realizadas aulas dialogadas, leituras de textos e rodas de conversas, problematizando a realidade vivenciada e o conhecimento prévio dos alunos.

Posteriormente, os grupos retornaram à realidade, para identificarem problemas de saúde da população e priorizarem um problema de saúde para a construção de uma proposta de intervenção em EPS. Devido ao tempo da disciplina, não foi possível realizar as propostas de intervenção nas comunidades; elas foram construídas e encenadas por cada grupo ao final da disciplina, como um exercício pedagógico de como desenvolver EPS junto com a comunidade.

A partir da sistematização dessa experiência, elencaram-se as seguintes categorias analíticas para avaliar esse processo: qualificação dos ACSs; qualificação dos graduandos de Enfermagem; dificuldades e potencialidades da prática pedagógica adotada, com vistas à Educação Popular em Saúde para o SUS. 


\section{Resultados e discussão}

\section{Qualificação dos ACSs em Educação Popular em Saúde: potencialidades e desafios}

De acordo com as atribuições dos ACSs na Política Nacional de Atenção Básica, observa-se que a Educação em Saúde é inerente ao seu trabalho na perspectiva da promoção da saúde, da prevenção de doenças e agravos e da vigilância à saúde ${ }^{17}$. O ACS trabalha por meio do diálogo com a comunidade buscando ser um agente educador ${ }^{18}$.

Tomando por base essa premissa, a disciplina aqui tratada se iniciou procurando conhecer saberes e práticas dos Agentes Comunitários de Saúde, bem como a realidade de suas microáreas de abrangência. Evidenciouse que eles realizavam atividades de Educação em Saúde da forma tradicional, ou seja, voltavam-se para a imposição de normas e comportamentos considerados, por eles, adequados. Esse resultado corrobora com um estudo que aponta que as ações educativas dos ACSs acontecem de forma individualizada, centrada na doença, no reforço da assistência médica e na prevenção de riscos específicos ${ }^{19}$.

Buscou-se, na disciplina, possibilitar aos graduandos de Enfermagem e aos ACSs a construção da compreensão de que as práticas educativas, no Brasil, estão diretamente associadas à concepção de saúde que prevalece em determinado modelo de atenção, vigente em determinada época, e que, diante disso, é fundamental resgatar a concepção de saúde do SUS, que ancora a EPS para a promoção da saúde.

Durante as aulas, ao discutir com os teóricos a realidade vivenciada nos momentos práticos, os agentes trouxeram a realidade dos serviços, a complexidade dos problemas de saúde e deram mais significados aos conteúdos. Isso foi possível porque eles possuem vínculo com as pessoas e conhecimento dos modos de vida da população ${ }^{20}$ e de suas necessidades de saúde ${ }^{18}$, além de vivenciarem as fragilidades dos serviços de saúde em garantir a atenção integral.

A participação dos ACSs na disciplina proporcionou o diálogo de saberes e potencializou o processo ensino-aprendizagem, ao articular saberes científicos e populares, ensinando e aprendendo ao mesmo tempo. Demonstrou-se, desde já, a importância do diálogo entre atores sociais diversos para a realização da Educação Popular em Saúde. Observou-se também uma grande participação dos ACSs nas discussões, manifestando, assim, o interesse de se envolverem em capacitações, especialmente sobre EPS. Isso pode ser resultado da revelação dos agentes da carência de investimento em cursos de qualificação para eles, o que reforça que a sua formação e qualificação é um grande desafio.

Estudos sugerem que há um processo inadequado de qualificação dos Agentes Comunitários de Saúde, pois recebem diversos microtreinamentos fragmentados, dados por diferentes programas, fora do contexto e sem uma sequência lógica ${ }^{13}$. É interessante perceber que eles ainda não recebem uma formação específica, nem obrigatória ${ }^{20}$. Sobre a formação em EPS, acrescenta-se a cultura de que não é preciso aprender a fazer Educação em Saúde ${ }^{1}$.

A experiência de capacitação dos ACSs, em articulação com graduandos de Enfermagem, em EPS para o SUS revela potencialidades, quais sejam: a realidade de trabalho dos agentes e seus saberes e práticas, a pedagogia da problematização, a discussão dos problemas de saúde identificados por eles e pelos alunos e de como realizar EPS a partir das necessidades de saúde da comunidade na perspectiva da promoção à saúde, articulação entre diversos atores e diálogo entre saberes.

Assim, evidencia-se a importância de tal experiência para o (re)pensar do processo pedagógico de capacitação desses atores do SUS, de modo a superar a maneira verticalizada e bancária de conduzir cursos de qualificação. Sobre esse assunto, Nascimento e Correa ${ }^{21}$, ao identificarem as contribuições de um curso de formação para ACS realizado em parceria entre universidade e secretaria municipal de saúde, constataram a relevância da pedagogia da problematização de Paulo Freire para uma formação que possibilite ao Agente Comunitário de Saúde refletir e intervir sobre sua realidade, assumindo o papel de sujeito educador e produzindo um conhecimento emancipatório, estimulando a reflexão e a capacidade de análise crítica.

Ao final da disciplina, os ACSs apontaram a necessidade de cursos de capacitação, haja vista que isso dinamizaria seu trabalho e traria motivação para eles; além disso, mencionaram a importância de ampliar essa experiência para outros ACSs. Os agentes também demostraram ter construído saberes 
sobre EPS e reconheceram que as práticas de Educação em Saúde tradicionais pouco contribuem para a promoção da saúde.

Mesmo diante dessas potencialidades, eles colocaram uma série de desafios para a implementação da EPS no seu trabalho, o que mostra que a formação é uma das dimensões do problema, mas não a solução. Entre os desafios, destacam-se: falta de apoio da gestão do SUS para a realização de ações de Educação em Saúde, incluindo estrutura física, material pedagógico e cursos de capacitação para os trabalhadores do sistema; precarização do trabalho; dificuldade de atuar de maneira intersetorial para a melhoria dos determinantes sociais de saúde da população; dificuldade de trabalho em equipe, sobretudo de articulação com a categoria médica; ausência de uma política permanente de qualificação dos agentes.

Após a finalização do curso de capacitação, realizou-se, por ocasião de visita dos docentes da disciplina à Unidade Básica de Saúde dos ACSs que se qualificaram, um diálogo com esses agentes e com a enfermeira da Estratégia de Saúde da Família sobre as possíveis repercussões do curso para o trabalho realizado pela equipe. Nesse momento, foram apontados avanços nas práticas educativas realizadas, como a maior autonomia dos ACSs para identificar problemas de saúde, planejar e executar ações de EPS coerentes com a realidade vivenciada no território e com respeito ao saber popular.

\section{Qualificação dos graduandos de enfermagem em Educação Popular em Saúde}

Os alunos de Enfermagem da disciplina Educação Popular em Saúde estavam no primeiro ano do curso de graduação. Nesse sentido, a disciplina constituía algo novo, com metodologias que envolviam contato com a realidade, diálogo com outros atores, discussão de textos, conhecimento/problematização da realidade dos serviços de saúde. Era o campo científico da universidade buscando desenvolver um aluno crítico e reflexivo. Esse processo pedagógico, em geral, era diferente do que eles estavam acostumados no ensino médio, o que implicou, portanto, um processo de adaptação dos acadêmicos a essas novas práticas.

A disciplina em questão representou, para os estudantes, a primeira aproximação com a realidade dos serviços de saúde do SUS, em especial, do PSF, e com as condições de vida da população. O fato de o território da área da equipe de PSF, campo de prática adotado, ser um bairro periférico do município, incluindo até mesmo uma favela, favoreceu a compreensão dos alunos de que os problemas de saúde não são apenas relacionados à ausência de doenças, mas envolvem trabalho, moradia, alimentação, transporte, lazer, acesso a bens e serviços, entre outros. Esse âmbito de prática contribuiu ainda para a discussão sobre o que é saúde, promoção da saúde e prevenção de doenças e agravos.

Os benefícios da incorporação da EPS na formação de enfermeiros têm sido relatados por outros autores. É nesse sentido que David e Acioli22 expõem que a realização de ações de extensão, tomando como base a EPS, desenvolvendo-se de modo articulado ao ensino, junto a grupos sociais populares, potencializam a formação de enfermeiros e se constituem em uma experiência importante para aproximar docentes, estudantes e profissionais de saúde dos vários contextos sociais, culturais e econômicos existentes, facilitando a possibilidade de diálogo e a troca de saberes. A ação pedagógica crítica da EPS permite ao enfermeiro "avançar numa análise mais aprofundada sobre as relações entre condições e modos de viver e a produção da saúde, para além dos processos biológicos imediatos"22 (p. 129).

O diálogo com os ACSs possibilitou, aos discentes do curso de graduação em Enfermagem da UERN, importância do trabalho em equipe no PSF, da articulação entre os diversos atores do SUS e do trabalho do Agente Comunitário de Saúde para a promoção da saúde. A relação de proximidade e diálogo entre alunos e ACSs foi harmoniosa e ambos puderam ensinar e aprender juntos. Percebeu-se um bom desempenho dos discentes durante a disciplina, decorrente do seu envolvimento com os temas trabalhados, dinamizados pela aproximação com a realidade da práxis dos ACSs e de vida da comunidade.

Apesar de ser o primeiro contato com os saberes e práticas da área de Educação em Saúde, priorizando a EPS como instrumento para as estratégias de consolidação do SUS, os alunos demonstraram, em seus conhecimentos prévios, o entendimento do que seriam as formas tradicionais de ditar normas e condutas transmitidas como corretas para a população, o que mostra que a Educação em Saúde tradicional está no imaginário das pessoas, no senso comum. 
No transcorrer da disciplina, essa compreensão foi mudando, ao se visualizar a historicidade do tema, a relação da Educação em Saúde com a concepção de saúde e as políticas de saúde vigentes em determinada época, além da importância da EPS para o SUS.

Os estudantes puderam perceber que, para o desenvolvimento da EPS, deve-se considerar o saber prévio do aluno/comunidade, seu contexto de vida e trabalho, problematizando-se os temas abordados a partir da realidade concreta e tentando-se construir um pensamento crítico e reflexivo sobre $o$ mundo. No que tange à EPS, ficou marcada sua importância para a desmistificação, por parte da população, da realidade aparente, com a problematização dos reais problemas de saúde e a instigação da participação popular em busca da promoção de saúde, contribuindo para o fortalecimento do controle social do SUS. Assim, coadunamos com David e Acioli ${ }^{22}$ ao afirmarem que a EPS permite avançar numa formação do enfermeiro voltada para a construção do projeto de saúde do SUS.

\section{A prática pedagógica do ensino da Educação Popular em Saúde para o SUS: dificuldades e potencialidades}

Vasconcelos ${ }^{23}$ aponta que muitas iniciativas educacionais nas universidades, especialmente em projetos de extensão, vêm sendo orientadas pela Educação Popular, e descobrem-se, aos poucos, os caminhos metodológicos de sua aplicação no contexto do SUS.

Estudos de autores como Santorum ${ }^{24}$, Firmino et al. ${ }^{25}$ e Ribeiro ${ }^{26}$ mostram que essas experiências de extensão, ancoradas na EPS, têm possibilitado aos futuros profissionais de saúde a construção de um pensamento crítico e reflexivo sobre os problemas de saúde, o desenvolvimento de competências que permitam a aproximação com a realidade de vida e saúde da população e o compromisso com a transformação dessa realidade, orientada pela defesa dos interesses públicos de saúde.

Nesse sentido, esses estudos estão em consonância com o processo pedagógico da disciplina Educação Popular em Saúde, aqui analisado, que contribuiu para a formação de um aluno crítico e reflexivo, capaz de conhecer e intervir no processo de produção dos serviços de saúde, com vistas a atender as necessidades sociais e a assumir um compromisso ético e político com a construção e consolidação do SUS ${ }^{27}$.

A disciplina teve como suportes teóricos a compreensão da Enfermagem como parte do trabalho coletivo em saúde e a percepção de que a articulação entre trabalho e educação se estabelece no processo ensinar/aprender, que resulta na produção da força de trabalho e tem como paradigma a concepção da educação como espaço de transformação capaz de produzir a força de trabalho de Enfermagem, comprometida com a transformação dos serviços de saúde e da sociedade em geral.

A Faculdade de Enfermagem (Faen) da UERN assume a articulação ensino-trabalho como um projeto político com uma nova concepção sobre o pensar/fazer na perspectiva de transformar a relação da construção do saber de teoria-prática para a relação prática-teoria-prática ${ }^{27}$. "Assim, o esforço para a construção do projeto político pedagógico da Faen é, por consequência, o esforço de construção da política de articulação ensino-trabalho"27 (p. 41).

Comprometidos com esses marcos teóricos e metodológicos, os docentes da disciplina de EPS tomaram a articulação ensino-trabalho como ponto-chave, a qual se destacou como uma potencialidade do processo pedagógico adotado.

Guizardi et al. ${ }^{28}$ colocam que, para os estudantes, os cenários de prática tornam-se espaços em que o conhecimento ganha vida e se confronta com desafios que exigem postura ativa, em que os componentes do currículo são mobilizados e articulados conforme os problemas colocados pela prática. Para os trabalhadores dos serviços, a proximidade com o discente os tem levado a refletir sobre sua prática e a buscar novos conhecimentos, o que os instiga à não-acomodação nas rotinas dos desafios apresentados pelo cotidiano do trabalho.

Entretanto, essa articulação entre atores da universidade e do SUS, no caso, estudantes de graduação e ACSs, não foi fácil e se constituiu em um desafio para os docentes. A primeira dificuldade encontrada para essa articulação acontecer na disciplina de EPS foi a falta de apoio da gestão do SUS. Esta apenas autorizou que os ACSs participassem dos encontros, mas não forneceu auxílio ao seu deslocamento para os encontros em sala de aula, na universidade; não incentivou a expansão dessa capacitação a outros agentes 
do município; não dialogou com a universidade sobre a importância da proposta para o SUS. Isso reflete a incipiência/falta de uma política de educação permanente do SUS municipal para seus trabalhadores e aponta a necessidade de haver uma maior parceria entre a gestão do sistema e a academia.

Ao mesmo tempo em que o diálogo entre saberes potencializa o processo ensino/ aprendizagem, ele constitui um desafio para os docentes, no sentido de conduzirem esse processo, articulando os dois públicos, e problematizarem saberes e práticas vivenciados pelos ACS, em especial, no que tange à Educação em Saúde, de maneira a (res)significá-los na perspectiva da Educação Popular em Saúde para o SUS. A EPS, mais que um instrumental metodológico, "é uma forma de conceber o mundo, pois indica uma ação educativa estritamente vinculada à reflexão com perspectiva de transformação" 26 (p. 345).

Entre as facilidades para o desenvolvimento da disciplina de EPS, destacaram-se o envolvimento e o desempenho dos graduandos de Enfermagem e dos ACSs nas atividades pedagógicas. Os conteúdos escolhidos e as metodologias adotadas com base na pedagogia da problematização apresentaram-se como potencialidades para o ensino de EPS para o SUS.

No entanto uma das dificuldades sentidas pelos docentes foi a localização da disciplina Educação Popular em Saúde no curso de graduação em Enfermagem, pois, como ela foi ministrada no primeiro ano do curso, os alunos ainda não tinham um conhecimento-base sobre concepções de saúde, políticas públicas de saúde e processo de construção e consolidação do SUS. Portanto, sugere-se que as ofertas das disciplinas de EPS, nos cursos de graduação, ocorram após os estudantes já terem acumulado, mediante outras disciplinas, conhecimentos básicos de Saúde Coletiva.

\section{Considerações finais}

A experiência de ensino, articulando Agentes Comunitários de Saúde e enfermeiros em formação, responde a uma dupla necessidade do SUS: reorientar os processos formativos de cursos de graduação em Saúde, no sentido de formar trabalhadores capacitados para a construção desse sistema; e qualificar os trabalhadores dos serviços para o exercício da EPS, aqui reconhecida como política pública importante à consolidação do SUS.

A necessidade de qualificação dos trabalhadores de saúde, quando se trata de EPS, recai, de modo especial, sobre os ACSs, em virtude da especificidade do seu trabalho que os coloca em permanente exercício de diálogo e Educação em Saúde com a população. Isso constitui um desafio para a universidade, haja vista a incipiência de políticas de qualificação, no interior do SUS, que assegurem, ao conjunto de seus atores, a capacitação suficiente ao exercício das ações de Educação em Saúde.

A multiplicação dessas experiências serve para mostrar a viabilidade, reafirmar a necessidade $e$ tencionar os demais atores, sobretudo gestores, profissionais e usuários, de/a perseguirem políticas de formação para os atuais e futuros trabalhadores, por se compreender isso como uma demanda nãosecundária à consolidação do SUS.

\section{Colaboradores}

Os autores trabalharam juntos em todas as etapas de produção do manuscrito.

\section{Referências}

1. Albuquerque PC, Stotz EN. A Educação Popular na Atenção Básica à Saúde no município: em busca da integralidade. Interface (Botucatu). 2004;8(15):259-74.

2. Alves VS. Um modelo de educação em saúde para o Programa Saúde da Família: pela integralidade da atenção e reorientação do modelo assistencial. Interface (Botucatu). 2005;9(16):39-52. 
3. Vasconcelos EM. Educação popular: instrumento de gestão participativa dos serviços de saúde. In: Ministério da Saúde. Secretaria de Gestão Estratégica e Participativa. Departamento de apoio à Gestão Participativa. Caderno de educação popular e saúde. Brasília (DF): Ministério da Saúde; 2007. p. 18-30.

4. Miranda MGO. Projeto político de formação do enfermeiro: contextos, textos, (re) construções [tese]. Natal (RN): Universidade Federal do Rio Grande do Norte; 2010.

5. Conselho Nacional de Educação. Câmara de Educação Superior. Resolução CNE/CES $n^{\circ} 3$, de 7 de novembro de 2001. Institui Diretrizes Curriculares Nacionais do Curso de Graduação em Enfermagem. Diário Oficial da União. 9 Nov 2001. Seção 1, p. 37 [acesso 2013 Jun 13]. Disponível em: http://portal.mec.gov.br/cne/arquivos/pdf/CESO3.pdf

6. Bourdieu P. O poder simbólico. 14a ed. Rio de Janeiro: Bertrand Brasil; 2000.

7. Tonet I. Educação, cidadania e emancipação humana. Ijuí: Unijuí; 2005.

8. Stotz EN. Enfoques sobre educação popular e saúde. In: Ministério da Saúde. Caderno de educação popular e saúde. Brasília (DF): Ministério da Saúde; 2007. p. 46-57.

9. Gomes LB, Merhy EE. Compreendendo a educação popular em saúde: um estudo na literatura brasileira. Cad Saude Publica. 2011;27(1):7-18.

10. Bornstein VJ. O agente comunitário de saúde na mediação de saberes [tese]. Rio de Janeiro (RJ): Escola Nacional de Saúde Pública Sergio Arouca; 2007.

11. Oliveira MW. Apresentação. Cad Cedes. 2009;29(79):297-306.

12. Benetti OP, Pedrosa JIS, Siqueira TCA. Educação popular em saúde como política do Sistema Único de Saúde. Rev APS. 2011;14(4):397-407.

13. Tomaz JBC. O agente comunitário de saúde não deve ser um "super-herói". Interface (Botucatu). 2002;6(10):75-94.

14. Ministério da Saúde. Secretaria Executiva. Programa Agentes Comunitários de Saúde (PACS). Brasília(DF): Ministério da Saúde; 2001.

15. Pedrosa JIS. Educação Popular no Ministério da Saúde: identificando espaços e referências. In: Ministério da Saúde. Secretaria de Gestão Estratégica e Participativa. Departamento de apoio à Gestão Participativa. Caderno de Educação Popular e Saúde. Brasília (DF): Ministério da Saúde; 2007. p. 13-7.

16. Ceccim RB, Feuerwerker LCM. O quadrilátero da formação para a área da saúde: ensino, gestão, atenção e controle social. Physis. 2004;4(1):41-65.

17. GM Portaria $n^{\circ} 2.488$, de 21 de outubro de 2011. Aprova a Política Nacional de Atenção Básica, estabelecendo a revisão de diretrizes e normas para a organização da Atenção Básica, para a Estratégia Saúde da Família (ESF) e o Programa de Agentes Comunitários de Saúde (PACS). Brasília (DF): Ministério da Saúde; 2011.

18. Jardim TA, Lancman S. Subjective aspects of living and working within the same community: the realities experienced by community healthcare agents. Interface (Botucatu). 2009;13(28):123-35.

19. Gomes KO, Cotta RMM, Mitre SM, Batista RS, Cherchiglia ML. O Agente Comunitário de Saúde e a consolidação do Sistema Único de Saúde: reflexões contemporâneas. Physis. 2010;20(4):1143-64.

20. Filgueiras AS, Silva ALA. Agente Comunitário de Saúde: um novo ator no cenário da saúde do Brasil. Physis. 2011;21(3):899-915.

21. Nascimento EPL, Correa CRS. O agente comunitário de saúde: formação, inserção e práticas. Cad Saude Publica. 2008;24(6):1304-13.

22. David HMSL, Acioli S. Mudanças na formação e no trabalho de enfermagem: uma perspectiva da educação popular e de saúde. Rev Bras Enferm. 2010;63(1):127-31.

23. Vasconcelos EM. Educação Popular: de uma prática alternativa a uma estratégia de gestão participativa das políticas de saúde. Physis. 2004;14(1):67-83. 
24. Santorum JA, Cestari ME. A Educação Popular na práxis da formação para o SUS. Trab Educ Saude. 2011;9(2):223-40.

25. Firmino R, Patrício J, Rodrigues L, Cruz P, Vasconcelos AC. Educação popular e promoção da saúde do idoso: reflexões a partir de uma experiência de extensão universitária com grupos de idosos em João Pessoa-PB. Rev APS. 2010;13(4):523-30.

26. Ribeiro KSQS. A experiência na extensão popular e a formação acadêmica em Fisioterapia. Cad Cedes. 2009;29(79):335-46.

27. Moura A, Miranda MGO, Lima MGA, Filho JB. O desafio da construção de marcos teóricos e metodológicos (re)orientadores da produção da força de trabalho de enfermagem no espaço da FAEN. In: Pinheiro R, Ceccim RB, Mattos RA, organizadores. Ensino-trabalho-cidadania: novas marcas ao ensinar integralidade no SUS. Rio de Janeiro: IMS, UERJ, Cepesq, Abrasco; 2006. p. 33-44.

28. Guizardi FL, Stelet B, Pinheiro R, Ceccim RB. A formação de profissionais orientada para a integralidade e as relações político-institucionais na saúde: uma discussão sobre a interação ensino-trabalho. In: Pinheiro R, Ceccim RB, Mattos RA, organizadores. Ensinar saúde: a integralidade e o SUS nos cursos de graduação na área da saúde. Rio de Janeiro: IMS, UERJ, Cepesq, Abrasco; 2005. p. 153-77. 
O presente artigo objetiva sistematizar e avaliar uma experiência de ensino de Educação Popular em Saúde (EPS) em curso de graduação em Enfermagem que inseriu Agentes Comunitários de Saúde (ACS) como discentes. A experiência possibilitou a qualificação dos ACSs, que puderam, mediante conteúdos e metodologias utilizadas, refletir sobre suas práticas de Educação em Saúde, caracterizadas pela imposição de normas e comportamentos, e construir instrumentos para a EPS. A troca de saberes com os ACSs e o conhecimento da realidade de vida/saúde da população possibilitaram aos alunos de Enfermagem construir uma concepção ampliada de saúde e compreender o caráter transformador da EPS no contexto do Sistema Único de Saúde (SUS). A experiência permitiu formar trabalhadores sintonizados com os desafios da construção do SUS e qualificar os ACSs para o exercício da EPS, reconhecida como política pública necessária à consolidação desse sistema.

Palavras-chave: Educação em Saúde. Educação Popular. Capacitação de recursos humanos em saúde. Agentes Comunitários de Saúde. Educação em Enfermagem.

\section{The teaching of Popular Education in Health for SUS: experience of articulation between nursing students and Community Healthcare Agents}

This article aims to systematize and evaluate a teaching experience of Popular Education in Health $(\mathrm{PEH})$ at undergraduate course in Nursing including Community Healthcare Agents (ACS) as students. The experience allowed the qualification of ACS, which could, through content and methodologies, reflect on their practices in health education, characterized by imposition of norms and behaviors, and create tools for Popular Education. The exchange of knowledge with the ACS and the awareness of the population reality of life/health enabled the nursing students to construct a broad view of health and understand the transformative character of EPS in the context of the Unified Health System (SUS). The experience allowed to train nurses in tune with the challenges of SUS building and to qualify ACS for the exercise of EPS, recognized as a public policy required for the consolidation of that system.

Keywords: Health Education. Popular Education. Enablement of human resources for health. Community Health Agents. Nursing Education.

La enseñanza de la Educación Popular en Salud para el SUS: experiencia de articulación entre los estudiantes de enfermería y de los Agentes Comunitarios de Salud

Este artículo pretende sistematizar y evaluar una experiencia en enseñanza de Educación Popular en Salud (EPS) en curso de enfermería, incluido Agentes Comunitarios de Salud (ACS) como estudiantes. La experiencia permitió capacitación de ACS, que a través de contenidos y metodologías, reflejaron sus prácticas de educación para salud, caracterizándose por imposición de normas, comportamientos y desarrollar herramientas para Educación Popular. El intercambio de conocimientos con el ACS y el conocimiento de realidad de vida/salud de la población hizo posible a los estudiantes de enfermería construir una visión expandida de salud y entender el carácter transformador de la EPS en Sistema Único de Salud (SUS). La experiencia ha permitido capacitar los enfermeros en sintonía con desafíos de construcción del SUS y calificar los ACS para el ejercicio de EPS, reconocida como una política pública necesaria a la consolidación de este sistema.

Palabras clave: Educación para la salud. Educación popular. Capacitación de recursos humanos para la salud. Agentes Comunitarios de Salud. Educación en Enfermería. 
